\title{
perifèria
}

Número 17, desembre 2012

www.periferia.name

\section{L'Àfrica com a experiència. Entrevista a Lluís Mallart}

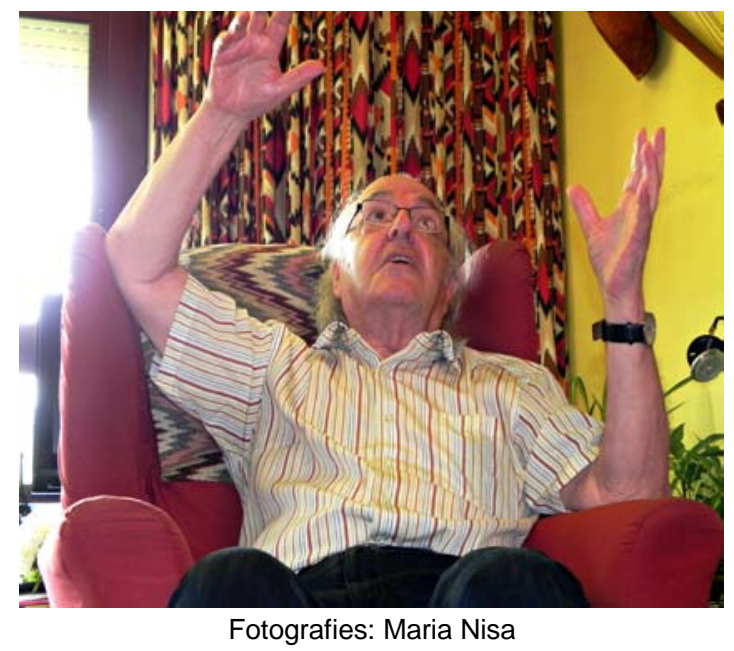

Autors: Nisa, Maria; Romogosa, Marta; Rué, Alèxia - Universitat Autònoma de Barcelona $(\mathrm{UAB})^{1}$

Directora: Montserrat Clua Fainé

Resum

Reprenem el Projecte Entrevistes publicant l'entrevista realitzada al gran etnògraf africanista català Lluís Mallart, especialista en els evuzok del Camerun. El professor Mallart i la seva esposa Neus ens van acollir amb hospitalitat africana a casa seva, van explicar-nos les experiències del jove capellà que va anar de Catalunya a l'Àfrica i com allà va descobrir el colonialisme religiós blanc i es va forjar la seva vocació antropològica. En el seu recorregut Mallart descriu la seva experiència amb l'etnologia francesa i els seus intents d'integrar-se a l'acadèmia catalana a través de la URiV. Mostrant-nos els seus diaris de camp i altres materials vinculats amb la seva extensa experiència etnogràfica, Mallart ens transmeté la seva experiència vital africana que li va permetre conèixer com ningú el món ritual i conceptual sobre salut, cos i malaltia entre els evuzok. ${ }^{2}$

\footnotetext{
${ }^{1}$ Enviar correspondència a: Montserrat.Clua@uab.cat

2 Informació etnogràfica que Mallart recollí en el llibre, La Dansa dels esperits (1985) i que just aquest any 2012 ha vist aparèixer la versió traduïda al castellà (Ceiba Edicions). L'edició inclou el DVD del documental sobre el llibre rodat per Ricardo íscar al 2009 i que es pot veure a: http://www.tv3.cat/videos/3347710.
} 


\section{perifèria}

Número 17, desembre 2012

www.periferia.name

\section{Resumen}

Retomamos el Proyecto Entrevistas publicando la entrevista realizada al gran etnógrafo africanista catalán Lluís Mallart, especialista en los evuzok del Camerún. El profesor Mallart y su esposa Neus nos acogieron con hospitalidad africana en su casa, donde nos explicaron las experiencias de juventud de un joven cura que fue de Cataluña a África, cómo allí descubrió el colonialismo religioso blanco y cómo se forjó su vocación antropológica. En este recorrido Mallart describe su experiencia en la etnología francesa, así como sus intentos de integrarse en la academia catalana a través de la URiV. Mostrándonos sus diarios de campo y otros materiales vinculados con su extensa experiencia etnográfica, Mallart nos transmitió su experiencia vital africana que le permitió conocer como nadie el mundo ritual y conceptual sobre salud, cuerpo y enfermedad entre los evuzok. ${ }^{3}$

\section{Introducció a l'autor: Lluís Mallart i Guimerà (Barcelona, 1932)}

Co-fundador d'Agermanament, Mallart se n'anà al Camerun l'any 1961 en qualitat de missioner i romangué entre els Evuzok fins el 1968. Aquell mateix any se n'anà a París a perfeccionar els seus estudis d'antropologia i obtingué el doctorat el 1971. Fou professor d'antropologia a la Universitat París-Nanterre (1971-92) i membre del Laboratoire d'ethnologie et sociologie del CNRS (Centre National de Recherche Scientifique) com a especialista en antropologia religiosa i mèdica. Al 1992 tornà a Catalunya a fer d'investigador a la Universitat Rovira i Virgili fins que es va jubilar. Ha fet missions d'estudi al Txad, Gabon, Mali, Congo, República Centre Africana i Afganistan. Entre les seves publicacions cal destacar: Un poble africà: etnologia i pastoral (1971), Médecine et pharmacopée Evuzok (1977), Ni dos ni ventre. Religion, magie et sorcellerie Evuzok (1981), La Dansa dels esperits (1985) i Sóc fill dels Evuzok (1993). Posteriorment ha publicat Okupes a l'Àfrica (2001), una punyent crítica al colonialisme i al paper exercit pels missioners en el continent africà, i La Forêt de nos Ancêtres (2003), una monografia en dos volums sobre el sistema mèdic i el saber botànic dels evuzok. El 2008 I'Institut d'Estudis Catalans li va publicar els dos volums en català: El Sistema mèdic d'una societat africana: els evuzok del Camerun. La Generalitat de Catalunya li reconegué la seva tasca científica mitjançant l'atorgament de la Medalla Narcís Monturiol al 1995.

\footnotetext{
3 Información etnográfica que Mallart recogió en el libro La Dansa dels esperits (1985) y que justamente este año 2012 se ha publicado la primera traducción al castellano (Ceiba Edicions). La edición incluye el DVD del documental que sobre el libro realizó Ricardo Íscar en 2009 y que se puede ver en: http://www.tv3.cat/videos/3347710.
} 
perifèria

Número 17, desembre 2012

www.periferia.name

\section{Pregunta: La nostra primera pregunta té a veure amb les etiquetes utilitzades per denominar la tasca dels antropòlegs. Des de l'Acadèmia es parla d'antropòlegs, d'etnògrafs i d'etnòlegs, tot i que les diferències no sempre són clares i sovint esdevenen complexes. Veient el seu bagatge, vostè com es defineix?}

Mallart: Jo m'he barallat amb mi mateix moltes vegades amb aquest tema, perquè -i us ho diré amb tota la franquesa del món -, quan vaig arribar aquí a Catalunya a mi sempre em deien que era un etnòleg i en canvi aquí tothom era antropòleg. Jo em preguntava si el que fèiem a França (que és el departament d'etnologia d'on jo procedia) era molt diferent del que es feia aquí. Potser eren mitjans diferents, però evidentment eren el mateix. Per altra banda, jo tenia la idea que es troba en algun dels escrits de LéviStrauss sobre les tres disciplines; i en els quals Lévi-Strauss diu que, de fet, no són tres disciplines diferents sinó que l'etnografia és un pas, l'etnologia n'és un altre i l'antropologia en pot ser un altre. És a dir, que l'etnografia la comences a fer recollint les dades, quan les compares fas etnologia, i quan es vol fer etnologia de moltes societats fent una reflexió més general esdevé l'antropologia.

D’altra banda, aquí tenia la sensació de que tothom començava per l'antropologia i deixava l'etnografia per fer la tesi i pels becaris. Una altra diferència molt forta que vaig trobar entre França i aquí era que els francesos en aquella època tots havien fet treball de camp, tots en fèiem i tots en continuàvem fent. I quan jo me n'anava a l'Àfrica tres mesos tothom ho trobava normal.

Tot i que en la meva opinió entre ells i jo no hi ha massa diferència, des del punt de vista de l'estatut que té l'antropologia i del que fem considero que

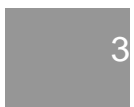




\section{perifèria}

Número 17, desembre 2012

www. periferia.name

hi influeix una part històrica. És a dir, als Estats Units o a Anglaterra en deien antropologia i a França van conservar el terme etnologia, tot i que ara comença a canviar perquè ven molt més la paraula antropologia que no pas la d'etnologia. Per tant, i contestant directament a la pregunta, us diré que sóc etnògraf i prou. I us diria també, com ja ho he dit en altres llocs, que és difícil fer etnografia sense fer l'etnologia i l'antropologia; i a l'inrevés...

P: Li hem sentit dir diverses vegades, inclús és una frase amb què molta gent el coneix, que vostè "va anar a l'Àfrica a convertir negres i els negres el van convertir a vostè en antropòleg". Creu que l'antropòleg, etnòleg o etnògraf es fa o és quelcom que es porta a dins?

M: Aquesta és una frase que vaig escriure en el Ilibre Sóc fill dels evuzok i és una manera de dir que cadascú és fruit de la seva època. Jo recordo quan era seminarista a Barcelona que organitzàvem colònies de vacances, que en aquella època no se'n feien. I d'una d'elles en vaig fer una espècie d'etnografia, escrita a màquina, on hi figurava el programa de cada dia, les reunions que fèiem de coordinació dels dies, el què havíem previst i el que finalment havíem fet, el que havia passat cada dia, els jocs que s'havien fet... Gairebé tres-centes o quatre-centes pàgines! No sé si es porta a dins, o no, però jo vaig començar així.

Som fruit de cada època en el sentit que nosaltres érem capellans joves: volíem estar amb la gent, volíem viure enmig del poble. I tinc la impressió de què un cop estant a Barcelona si sorties de capellà i et destinaven a una parròquia burgesa de la capital era com una desgràcia. Nosaltres preferíem anar a parròquies obreres... Potser era l'esperit d'aquella època...! A mi em 


\section{perifèria}

Número 17, desembre 2012

www.periferia.name

van enviar a Esparreguera on m'ho vaig passar molt bé i vaig fer moltes coses. Era un capellà molt actiu!! Molts de nosaltres volíem sortir d'un esquema eclesiàstic clàssic. El fet de voler anar a l'Àfrica es va moure també en aquest esperit: volíem que la diòcesis de Barcelona esdevingués una església missionera, oberta als altres, a les altres religions i cultures... Potser caldria dir-ho més endavant però ho diré ara: fins i tot quan érem al Camerun se'ns va ocórrer crear un Institut d'Estudis Africans a Barcelona, però no vàrem tenir mitjans per fer-ho...

Al trobar-me al país evuzok vaig esdevenir antropòleg gairebé sense volerho. La primera cosa que em calia fer era intentar conèixer les maneres de fer i de pensar del poble on vivia, una mica per seny i per una raó gairebé bíblica que diu que "el bon pastor ha de conèixer les seves ovelles". És una manera de dir; allí d'ovelles no ni havien (ni em creia ser massa un bon pastor), només persones i les havíem de conèixer. Jo era un estranger que si volia viure allí em calia aprendre a parlar la llengua i a conèixer una mica aquella societat... I això, quan es vol fer una mica ben fet també en podem dir etnografia, encara que llavors a penes en sabia el nom...

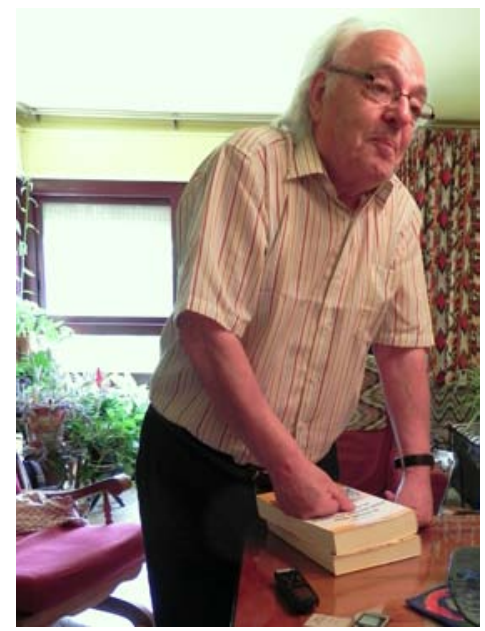




\section{perifèria}

Número 17, desembre 2012

www.periferia.name

El primer pas que jo vaig fer un cop havia descobert l'etnografia va ser escriure a un amic meu estudiant de jesuïta que estudiava lingüística als Estats Units, en Xavier Albó, ${ }^{4}$ per parlar-li de les meves cuites antropològiques. Ell em va aconsellar que llegís El pensament salvatge de Lévi-Strauss. Va ser gràcies a aquell amic que vaig començar a descobrir l'estructuralisme. En aquell moment acabava de llegir Lévi-Bruhl, Les funcions mentals de les societats inferiors, que era el contrari de LéviStrauss i per mi va ser una alenada d'aire fresc. Em va ajudar moltíssim a seguir endavant. Després vaig llegir a Marcel Mauss, Drukheim... i a altres clàssics de l'antropologia. En plena selva... amb tota tranquil·litat... I així va ser com vaig esdevenir antropòleg sense saber-ho.

A l'Àfrica els primers passos que vaig fer com a etnògraf els feia per conèixer el país en el qual estava. Aquella primera etnografia estava marcada per una preocupació missionera: evangelitzar millor per contribuir a fer una església pensada en termes africans i no occidentals. Perquè a mi em posava "negre" dir la missa en llatí. O veure com, per exemple, l'ús dels colors i altres símbols eren signes occidentals que no tenien res a veure amb la realitat africana. Entre els evuzok el blanc era el color de la mort i per a nosaltres el de la resurrecció, la puresa... A nivell lingüístic el blanc està relacionat amb la brutícia: un negre quan s'embruta queda blanc...! I coses encara més greus: "el nostre pa de cada dia". El pa? De cada dia? Els evuzok sabien que els blancs menjaven una cosa que es deia "pa" i que hom podia trobar a $150 \mathrm{~km}$, a la ciutat de Kribi on vivien alguns blancs...

\footnotetext{
4 Xavier Albó nasqué a La Garriga (Catalunya) i es feu membre de la Companyia de Jesús. Emigrà a Bolívia el 1952 i es va nacionalitzar ciutadà bolivià. És doctor en Lingüística Antropològica per la Universitat de Cornell, Nova York (1966-70); Ilicenciat en Teologia de la Facultat Borja, Barcelona (1961-4) i de la Loyola University de Chicago (1964-5). Font: http://albo.pieb.com. bo/albo.htm
} 


\section{perifèria}

Número 17, desembre 2012

www.periferia.name

Coses d'aquest tipus. La casa del capellà havia d'estar separada del poble i jo me'n vaig anar a viure en un poblet i a casa d'un polígam! Jo havia de condemnar als polígams i a la segona dona no la podia batejar... i ho vaig fer. Sort que tenia el bisbe a tres-cents quilòmetres! En aquest sentit vaig ser mal capellà. Però era bon capellà en el sentit de que intentava estar amb la gent, anar a tots els pobles...

P: Hi ha una part de la seva vida que queda desdibuixada i és: què porta un jove de Sarrià, que volia ser contable, a anar-se'n al 1961 a missions a l'Àfrica? Sabem que vostè va anar a Burgos, que va passar per Esparreguera. Però, què va passar fins arribar a l'Àfrica? M: A Sarrià vaig tenir la sort de fer bons amics. Primer els del barri. Sempre ho he dit - inclús ho he escrit en el llibre de Sóc fill dels evuzok- que l'etnologia del carrer encara està per fer. Perquè certament jo vaig viure molt al carrer. Després d'estudiar als Germans $^{5}$ vaig anar a l'Institut Tècnic Eulàlia i allà vaig fer-me molt amic amb el Josep Montserrat, que va ser professor de filosofia a I'UAB, i amb en Raventós. Cap dels tres vam tenir contacte amb altres ambients com podria ser un ambient polític. Sarrià era una parròquia burgesa i l'únic mitjà que vam trobar a les nostres mans va ser l'Acció Catòlica. Els diumenges venien uns jesuïtes a fer catecisme per adults i ens vam fer amics. Però era un catecisme diferent: ens parlaven de filosofia (eren estudiants de jesuïtes), del Japó, de l'Índia, volien anar al Japó a ser missioners. I nosaltres érem uns tendres adolescents! Fou així que tinguérem contacte amb altres jesuïtes originaris de l'índia... I potser

\footnotetext{
${ }^{5}$ Mallart es refereix a l'escola Germans de les Escoles Cristianes de la Salle, popularment coneguts com a Germans de La Salle de Sarrià (Barcelona).
} 


\section{perifèria}

Número 17, desembre 2012

www.periferia.name

va ser per això que va néixer la idea de fer-nos missioners i en Josep Montserrat i jo vam anar a Burgos junts. Jo m'hi vaig estar quatre anys a Burgos, però passàvem gana...! I allí els catalans vam fer una petita revolta, pensàvem el fet de ser missioners d'una manera diferent... i vam tornar a Barcelona. Penseu que a Burgos, durant el temps que hi vaig estar, no vam sentir mai a parlar del colonialisme..., era molt fort.

Després quan vam tornar a Barcelona vam crear un grup de reflexió sobre Àfrica que es deia Negritud. Aquí a Barcelona tampoc se'n parlava gaire de negritud ${ }^{6}$ però a França se'n parlava molt. I amb aquest esperit vam anar pensant diferentment la nostra manera "d'anar a missions", que la concebíem com una forma de crear un "agermanament" entre pobles i de posar-nos al servei de les noves esglésies africanes. I fou així que vam crear un moviment que es va dir precisament Agermanament, que pretenia agermanar l'església de Barcelona amb la jove església de Douala, al Camerun.

Jo vaig escriure una sèrie de reflexions que vaig fer mentre estava a Nsola, sobre la realitat dels pobles bantú i el missatge cristià, que després es van publicar en un Ilibre de l'editorial Estela que es deia Un poble africà: etnologia i pastoral. Diria que molt poca gent en va fer cas. En aquella època es tenien altres preocupacions; era els anys finals del franquisme... Va ser un Ilibre que va sortir publicat quan jo estava a França (1971) i fins i tot a mi, quan el vaig veure publicat, em va caure l'ànima als peus, perquè ja no creia massa en allò que havia escrit. Mentrestant m'havia convertit en etnògraf, etnòleg o antropòleg... a seques. Perquè aquell llibre era com,

\footnotetext{
${ }^{6}$ En paraules del propi Mallart, moviment que pretenia que el món es mirés amb uns altres ulls el continent africà, els seus valors i el seu afany per reivindicar la independència.
} 


\section{perifèria}

Número 17, desembre 2012

www.periferia.name

diguem-ho d'aquesta manera, una reflexió per fer una església africana o que tingués en compte la manera de fer africana. Però quan el van publicar ja havien passat uns anys i jo havia canviat. Havia descobert que existia una incompatibilitat entre el treball de missioner i l'antropologia. És a dir: jo com a "bon capellà" no podia viure a casa d'un polígam i jo ho feia. Tampoc podia passar-me tres dies a casa d'un medecinaire i també ho feia. És a dir, que des d'un punt de vista oficial de l'església la meva manera de pensar i de fer no era massa ortodoxa (jo feia disbarats i sabia que eren disbarats). Intentava introduir algunes reformes africanitzant, per exemple, la litúrgia. Però jo no era ningú per fer-ho, no era ningú! En tot cas eren els propis africans els que ho havien de fer... És a dir, jo podia comprendre més o menys la llengua, inclús intentar-la traduir com vam fer..., però introduir una reforma... I és així, sota aquestes circumstàncies, com mica en mica vaig dedicar-me a l'antropologia i les meves preocupacions evangelitzadores van anar desapareixent. Ara, aquest llibre, Etnologia i pastoral, va servirme per entrar a la Universitat de Nanterre (1968). Perquè quan vaig saber per un anunci al diari que buscaven un etnòleg, vaig enviar el meu currículum i un exemplar del llibre.

\section{P: Després de la seva primera estada al Camerun i descobrir} l'antropologia vostè se'n va a l'École a París a formalitzar aquesta vocació en estudis universitaris. Per què escull París i no torna a Catalunya?

R: Home, la qüestió és que estava al Camerun i el Camerun era d'expressió francesa i sabia que a França existia una gran tradició etnològica. Tots els 


\section{perifèria}

Número 17, desembre 2012

www.periferia.name

Ilibres que havia llegit estant al Camerun em venien de França... Era molt més possible trobar coses a França que es relacionessin amb el món de l'etnologia que jo havia estudiat des d'Àfrica. Aquí, a Espanya, no en tenia cap de llibre; a penes es publicava res d'antropologia i encara menys d'etnologia africana... La majoria de llibres són en francès. Recordo que vaig escriure a algú de casa nostra per veure què hi havia a la nostra universitat en el camp de l'antropologia. En aquella època només hi havia les classes sobre els pobles primitius a Barcelona que feia l'Agustí Panyella, que era el director del Museu Etnològic. Què hi havia l'any 68 aquí? Gairebé res!

\section{P: A l'any 68 hi havia el Claudi Esteva Fabregat a Madrid, que a Barcelona no hi havia arribat. I la Universitat Autònoma encara s'havia de fer...}

R: L'Autònoma encara s'havia de fer... Aleshores me'n vaig anar a França. Però primer vaig anar a la ciutat de Kribi, que era la primera ciutat que tenia cara i ulls del Camerun. I allà escolto a la radio que els estudiants de França estaven en vaga: era el maig del 68. Me'n vaig anar igualment a França pensant: "ja els hi passarà". Vaig anar a Grenoble, ja que a Kribi vaig assabentar-me de que a la universitat de Grenoble hi feien un curs de lingüística africana. Jo en aquells moments no tenia ni cinc i en l'anunci deia que feien un preu especial per a les persones que tenien problemes econòmics, era una cosa molt oberta. I vaig anar a la universitat de Grenoble. Allà va ser la meva primera gran descoberta, en trobar-me amb un gran equip de professors especialistes en lingüística africana. Entre els professors hi havia bastants jesuïtes de Lió. La qüestió es que en el 


\section{perifèria}

Número 17, desembre 2012

www.periferia.name

laboratori de lingüística de la universitat hi havia cabines per poder estudiar els sons de les diferents llengües africanes. Érem unes 40 o 50 persones estudiant en aquest curset d'estiu: algunes que se n'anaven cap a l'Àfrica i d'altres que en tornaven i que, com jo, havien après una llengua però sense coneixe'n bé l'estructura ni els principis generals de la lingüística. Ho havíem fet tot a partir dels mitjans que teníem. Aquella llengua tenia una petita gramàtica i diccionaris - el que encara tinc a sobre de la taula, per exemple, i que encara faig servir -. I van ser uns dies deliciosos, però també de molta frustració. Hi havia una bona biblioteca i una llibreria plena de llibres de lingüística africana i etnologia.... i jo no tenia ni cinc per comprar-los!

Total, que vaig tornar a Barcelona i això va confirmar més la meva idea de tornar-me'n a anar a París a fer un "reciclatge". Haig de dir que llavors tampoc no tenia massa la idea de treure'm un diploma o un doctorat... Era un moment d'una petita confusió mental: pensava plegar de l'església, pensava no plegar de l'etnologia,... eren moltes coses. Tenia els materials, però continuava sense calers. Vaig apuntar-me com a "oient" a alguns cursos. Vaig obtenir un ajut d'Agermanament per fer aquella estada a París, que era per viure però res més; era molt petit. Llavors em vaig assabentar de que a París, a l'École Practique des Hautes Études, hi havia una secretaria molt oberta que feia la inscripció sense fixar-se massa en la qüestió de l'edat (al setembre del 68 hi havia un esperit molt obert per part de tothom a la capital francesa). I això de l'edat era important en mi, perquè si tenia més de 35 anys no podia tenir una carta universitària que permetia anar al restaurant universitari i al cinema amb el $50 \%$ de descompte. Així va ser com vaig descobrir l'École Practique. Això vosaltres 


\section{perifèria}

Número 17, desembre 2012

www.periferia.name

no sabeu que és però l'École és una institució acadèmica molt prestigiosa a França i que encara existeix. Va ser fundada per Napoleó i és una escola orientada en la formació per a la recerca en les grans disciplines: ciències, sociologia, religió, matemàtiques, filologia antiga,... Moltes disciplines alhora. Per inscriure't no cal cap requisit especial, ni tan sols tenir el batxillerat. Jo no tenia batxillerat! Vaig estudiar comerç i de comerç me'n vaig anar al seminari. Tenia la carrera de capellà, però la carrera de capellà no serveix per res - des del punt de vista oficial -. Em van arribar a convalidar la carrera de capellà donant-me l'equivalència de batxiller.

Aquesta escola es d'aquesta manera, és Iliure. Si el director del seminari en què et vols inscriure t'accepta i accepta dirigir el teu projecte de recerca, ja en tens prou... En aquell temps almenys era així. El director d'estudis dedicava el seu seminari per a parlar de les seves pròpies recerques i els alumnes parlaven de les seves... Mentrestant, sota la direcció del director, anaves preparant la teva tesi per tal de que al cap de dos anys obtenir el diploma. Llavors es veuria si ets capaç o no. I va ser així com vaig entrar. Al principi em vaig inscriure pel tema del francès i del carnet per anar a dinar i al cine a bon preu. Però llavors vaig inscriure'm de debò.

Jo vaig inscriure'm en un seminari on el tema era: “L'arbre en el contes africans". I vaig fer-lo durant dos anys. La directora era la Geneviève Calame-Griaule, la filla del Marcel Griaule. Aquell seminari es va acabar amb una publicació conjunta sobre aquell tema.

I un dia la Geneviève Calame-Griaule em va dir: "fes l'exposició de les teves recerques sobre la medicina". Vaig portar un parell de dossiers sobre el tema i vaig fer l'exposició. Llavors va demanar-me que li deixés els dossiers per veure-ho. A la setmana següent vam parlar i em va dir: 


\section{perifèria}

Número 17, desembre 2012

www.periferia.name

“Home, per què no fas la tesi a l'École, si tens material de sobres?!" I jo li vaig dir: "Tinc 25 dossiers més a casa". A partir d'aquí vaig fer el diploma sobre la medicina tradicional. Després vaig preparar el doctorat sobre el tema de la religió i la màgia evuzok.

Vaig tenir molta sort. Havia decidit deixar la feina de capellà. Estava acabant la tesi de doctorat sota la direcció de Denise Paulme, una africanista molt estimada en el món de l'antropologia africana, deixeble de Marcel Mauss. I vaig començar a buscar feina. Pensa que jo vaig entrar a Nanterre per un anunci al diari Le Monde i sense fer oposicions, cosa que aquí no passa. Vaig llegir en un anunci que al departament d'etnologia de la Universitat de Nanterre necessitaven un etnòleg africanista amb experiència de terreny. A França no existeix el sistema d'oposicions. Un esdevé professor de la universitat per currículum, competint amb especialistes membres de la casa i de fora, com està establert per llei. Hi ha una comissió d'especialistes que examina les candidatures i elegeix. En la meva hi havia Lévi-Strauss...

L'anunci que vaig llegir a Le Monde era per a una substitució d'un any, per un professor que se n'anava a fer un any de treball de camp a l'Amazones. Llavors necessitaven un substitut i el departament va decidir que volien un africanista amb experiència al terreny. Era només per un any i vaig haver de buscar feina una altra vegada. A Nanterre van dir-me: "procura no desaparèixer massa de la plaça de París" i vaig continuar fent classes un temps. Però no podia viure d'això. Llavors vaig llegir un altre anunci a Le Monde on un Bureau d'Etudes (CINAM) buscava un enginyer agrònom per anar a l'Àfrica. Jo sabia qui era la CINAM que havia treballat al Camerun. Vaig escriure a l'empresa dient: "Jo no soc enginyer agrònom ni res per 


\section{perifèria}

Número 17, desembre 2012

www.periferia.name

l'estil..." Jo no sé plantar cap patata ni cap mongeta! "He viscut al Camerun, sóc etnòleg i sé fer això, això i això. I ara me'n vaig de vacances a Espanya". I em van contestar dient: "Marxi tranquil.lament de vacances i quan torni vingui'ns a veure". I els vaig anar a veure i van oferir-me una plaça que era d'anar amb equips una temporada a l'Àfrica 15 dies- 1 mes en missions d'estudi. Vaig anar-hi amb la Neus i vam estar 3 mesos a l'Afganistan. Això em permetia viure i estar a París. Això era molt al principi. En tornar hi va haver eleccions a Nanterre, vaig presentar de nou la meva candidatura i vaig guanyar la plaça. I així va ser com vaig entrar a Nanterre.

\section{P: Com vostè ha comentat, tota la seva carrera professional ha estat} a Nanterre. En algun moment s'ha plantejat tornar a Catalunya?

R: En aquell moment jo estava a París amb unes condicions molt bones. Vaig passar tots aquells 25 anys fent 6 hores de classe per setmana, assistint al seminari mensual del laboratori, anant al laboratori d'investigació... I, com que tenia tot el temps, podia dedicar-me a fer recerca sense haver d'anar a la universitat, ja que a la universitat només hi havia d'anar dues vegades per setmana i treballava molt a casa. Ara, a mi m'agradava molt escriure en català i sempre que podia, allò que escrivia, per exemple La Dansa dels esperits (1985), ho escrivia en primer en català. Vaig intentar mantenir contactes amb gent del món universitari de casa nostra. Va ser així com van venir els companys de la Universitat de Tarragona (Universitat Rovira i Virgili) per proposar-me venir aquí a Catalunya a integrar-me en el sistema universitari català. Aquí és on comença la historia... però aquesta és una altra història... 


\section{perifèria}

Número 17, desembre 2012

www.periferia.name

Des de la cosa professional em feia il-lusió tornar a Catalunya, però per tot un conjunt de coses, finalment no va poder ser. D'aquest període, el meu pas per la Universitat Rovira i Virgili, vull recordar la creació d'un Postgrau d'Estudis Africans en el que hi participaren antropòlegs africanistes molt prestigiosos. Llàstima que tot va ser massa tard i la meva jubilació va fer que aquells estudis que havíem iniciat desapareguessin completament... També recordo amb satisfacció la meva col·laboració en la creació d'un màster d'antropologia mèdica...

Després va venir la jubilació... potser una mica anticipada, als 65 anys... El meu estatut, l'estatut amb el que vaig integrar-me a Catalunya un cop arribat de França no em permetia anar més lluny... Ja fa més de 15 que estic jubilat. Visc a Olot. He pogut treballar fent recerca més que mai, escrivint, organitzant i digitalitzant jo sol tots els meus arxius...

Jo a Barcelona no pertanyo a cap grup acadèmic. Deu ser la condició una mica especial dels investigadors jubilats... De tal manera de que em vaig adonar que aquí no participava en això que feu vosaltres ara d'exposicions, conferències, ...etc. Sóc membre del laboratori de Nanterre, però ja em vaig adonar que aquell estatut no em permetia fer certes coses que feu aquí. Era un investigador, però no un professor com els altres. Podia estar en el tribunal d'una tesi perquè sóc doctor, però no podia anar a un tribunal d'oposicions. L'única universitat de casa nostra que, un cop jubilat, va ser sensible a la meva situació va ser l'Autònoma (Universitat Autònoma de Barcelona). La UAB sempre ha estat molt correcte amb mi. Fins i tot em van oferir un despatx sempre que volgués venir a Barcelona i fer cursos en el doctorat. Sempre ho agrairé. Però com sabeu, a mi em van operar i com que teniu la mala costum de viure allà a sobre d'aquella muntanya, no vaig 


\section{perifèria}

Número 17, desembre 2012

www.periferia.name

poder acceptar. Em costava arribar a dalt, al departament que està al capdamunt de la muntanya...! Però vull dir que l'Autònoma sempre ha estat molt correcte amb mi.

Recordeu una cosa, que he dit moltes vegades: el gran privilegi nostre és que fem una feina que ens agrada i a més a més ens paguen; cap fortuna, però ens paguen. Que facis allò que t'agrada i que a més a més tinguis un sou a fi de mes, és extraordinari! I fins i tot durant la jubilació, i la jubilació és un temps beneït per a continuar les teves recerques... En silenci, sense necessitat de fer-ho per allargar un currículum vitae...

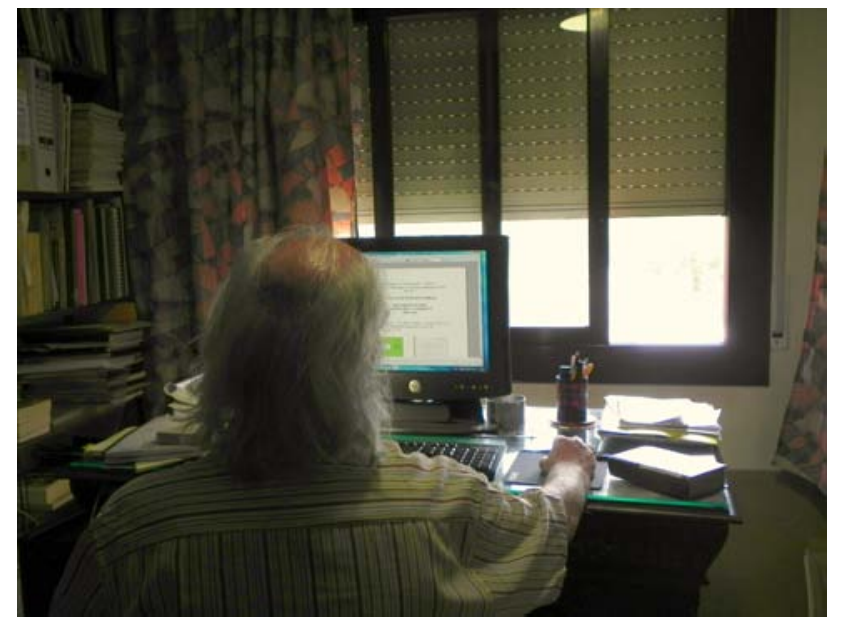

P: Canviant una mica de tema, parli'ns de la diferència que hi ha entre l'antropologia espanyola i la francesa...

R: La primera cosa és la importància que hem donat al nostre departament de Nanterre. El nostre departament era una cosa que estava molt bé - ara les coses potser han canviat -. Era el departament d'antropologia on es feien els màsters o els postgraus i els ensenyaments. I després hi havia el 


\section{perifèria}

Número 17, desembre 2012

www. periferia.name

laboratori, que estava format per investigadors del CNRS (Centre National de la Recherche Scientifique) o d'altres organismes de recerca com és I'École (EHESS) i pels professors del departament. Aquest laboratori era mixt: hi havia els investigadors del CNRS i els professors de la universitat físicament junts, anava lligada una cosa amb l'altra. Els investigadors participaven en l'ensenyament i els professors teníem un marc per a fer les nostres recerques.

La qüestió és que era una avantatge molt gran com ho teníem en aquella època. Totes les àrees estaven representades: Àfrica, Amèrica, Oceania, Europa, etc. I la majoria de temes - els clàssics - hi eren investigats. I eren cursos bastant especialitzats. Els professors eren realment especialistes, investigadors en la matèria que tractaven a classe, sobretot a nivell de la maîtrice.

No ho teniu vosaltres aquí això, oi? Aquest Iligam entre el CNRS (o el seu equivalent) i l'ensenyament no existeix aquí, no?

\section{P: El què més s'hi assembla és el CSIC però no té cap vinculació amb l'acadèmia.}

Allà hi havia molta relació entre professors i investigadors en el marc d'una mateixa institució. En aquella època el laboratori d'investigació i el departament d'etnologia estaven en el mateix edifici. Ara són dos edificis separats; han fet un edifici gran d'etnologia i prehistòria. L'esperit és el mateix encara que les coses han evolucionat...

\section{P: Potser a França es dóna més èmfasi al treball de camp...}

R: A França es realitzava més treball de camp, almenys a la meva època. 


\section{perifèria}

Número 17, desembre 2012

www.periferia.name

Això era un element molt important. Ningú s'estranyava que jo tornés al mateix Iloc, al Camerun, a continuar les meves recerques. Ara la cosa s'ha complicat més, s'ha complicat el món i és més difícil anar a un lloc o a un altre, però en aquella època era possible.

Estant a Tarragona encara vaig anar com a membre del laboratori al Camerun a passar-hi un parell de mesos. Uns collegues que anaven al Camerun em van dir: per què no véns amb nosaltres i anem a fer treball de camp...? I vaig anar-hi un parell de mesos. No ens donaven cap fortuna; quan hi anàvem nosaltres ens donaven pel viatge d'anada i tornada i una miqueta pel dia a dia. No havia de treure res del meu sou però tampoc hi afegia res. Et permetia d'anar de treball de camp; no anàvem allí a l'hotel de primera, nosaltres vivíem a la selva...

\section{P: Des de l'antropologia a vostè se'l coneix principalment pel llibre} Soc Fill dels Evuzok, que de fet a sigut un dels llibres més mediàtics de I'antropologia de casa nostra. Però per a qui no és especialista però que li agrada viatjar i passa per l'Àfrica es coneix també a Mallart a través d'Okupes a I'Àfrica. Creu que se I'ha identificat massa amb aquestes dues obres?

R: De fet jo he dit alguna vegada que, home! també he fet altres coses. Sóc fill dels Evuzok el vaig començar a escriure a París. I escolta'm, he fet d'altres coses. Per mi continua essent... ha sigut un llibre que s'ha anat venent perquè vosaltres I'heu recomanat molt. Ara, és veritat que ha anat sortint. No sé perquè; hi ha llibres que surten. Mira, estava a París i aquest llibre vaig fer-lo gairebé per equivocació. No, per equivocació no, però vull dir que un dia va venir el Jordi Porta, director de la Fundació Bofill i em 


\section{perifèria}

Número 17, desembre 2012

www.periferia.name

va preguntar què feia. I jo li vaig dir que volia fer un llibre que articulés tot el que havia anat escrivint sobre el sistema mèdic evuzok. Resulta que un dia fas una tesi, un altre dia escrius un article,... i volia publicar tot el que feia referència a les meves recerques sobre el sistema mèdic del poble evuzok però com un tot, en un llibre ben estructurat. Em va dir que si presentava un projecte la Bofill em podia ajudar a tirar-lo endavant. Però el meu projecte era escriure quelcom sobre aquest tema en tres o quatre volums... Van trobar que era una mica excessiu i massa tècnic... Llavors em va proposar d'escriure un llibre més planer de com havia esdevingut antropòleg. I em van donar diners per escriure aquest llibre.

En aquella època jo encara era a París i al cap de poc vaig venir aquí. El compromís era d'escriure aquest llibre i prou. I llavors el vaig escriure; vaig estar-m'hi un temps. I no sé perquè, vaig parlar d'aquest llibre amb l'amic Bernades de la Llibreria Altaïr i em va dir: "Et presentaré als de l'editorial La Campana". I a la Campana els hi va agradar i el van publicar. I aquest Ilibre s'ha anat publicant: n'han fet cinc edicions, s'ha traduït al castellà i a l'italià... i van canviar la portada i tot. Però va arribar un moment que ja n'estava una mica cansat d'aquest Ilibre! Fins i tot vaig dir a la família: "El dia que em mori, poseu a l'esquela: Lluís Mallart Guimerà, fill dels Evuzok... I els drets d'autor... per a la vídua...!"

He escrit d'altres coses, he fet d'altres coses de les que no s'ha parlat tant i de les que acadèmicament n'estic més satisfet. Jo estic molt satisfet dels Ilibres publicats per I'Institut d'Estudis Catalans (IEC). Aquest Ilibre que són dos volums, El Sistema mèdic d'una societat africana: els evuzok del Camerun (2008) i que està tant ben editat! Presenta molt bé el que han sigut les meves recerques sobre el sistema mèdic dels evuzok. Aquestes 


\section{perifèria}

Número 17, desembre 2012

www.periferia.name

coses la majoria han estat escrites en francès. Des del punt de vista editorial i científic l'I nstitut ha fet una feina extraordinària. Perquè, com s'escau en aquestes obres, mai van plantejar-me si hi havia massa notes o massa textos en ewondo o altres coses. No, no...! En el segon volum hi ha molt material etnogràfic: hi ha dues-centes receptes escrites en la llengua ewondo (la llengua evuzok) amb la traducció al català; un manuscrit d'un medecinaire escrit també en ewondo; un repertori de 500 plantes... És un diccionari, una enciclopèdia d'etnobotànica de tots els materials que he anat recollint jo. I tot això en català. Ho vaig escriure en català perquè m'agrada escriure en català.

Però no han sigut els antropòlegs els que han publicat aquest llibre; han sigut els lingüistes. Ha sigut la Carme J unyent, lingüista de la Universitat de Barcelona, que va proposar la seva publicació a la càtedra UNESCO del I EC. Van tardar bastant, perquè és un llibre amb tot els ets i els uts. Jo estic més orgullós - per dir-ho així- d'aquest llibre, perquè és una obra científica, mentre que Sóc fill dels evuzok és un llibre més divulgador. L'estil no és el mateix. Al Sóc fill dels evuzok hi ha un aspecte més narratiu, més planer. En canvi El sistema mèdic és més auster, impossible de ser publicat per una editorial comercial. El problema de les editorials no comercials és que funcionen a partir de subvencions per editar aquests llibres i la comercialització i la difusió és més complicada... I aquest és un llibre en català; gairebé has de donar les gràcies de que et publiquin un llibre com aquest. De totes maneres, a mi ja m'està bé que estigui a les biblioteques, a la universitat... Ara és veritat que Sóc fill dels evuzok ha estat més conegut. 


\section{perifèria}

Número 17, desembre 2012

www.periferia.name

P: Molta gent coneix la segona part, que és Okupes a l'Àfrica. Aquest llibre també ha tingut molta sortida amb la gent que no es dedica a l'antropologia però que viatgen i tenen aquesta dèria per I'Àfrica... Diuen que la "malaltia africana" afecta molt.

R: A París diuen, On est mange par l'Afrique. A mi, la "malaltia africana" m'ha afectat molt, encara em dura... Podria haver pensat que la jubilació em curaria, però no ha estat així. M'he dedicat a moltes coses relacionades amb l'Àfrica amb les meves recerques. Però més que parlar del passat m'agrada parlar del present. Ara m'he pogut dedicar a la digitalització dels meus materials etnogràfics que restaran com a fons en els arxius de la Universitat de Nanterre. Després m'he dedicat a explorar el joc de I'Abia. És un tema sobre el que he anat treballant durant 40 anys. Va ser un projecte de tesi de doctorat sobre el qual vaig parlar-ne amb el meu director de tesi. Però em van dir que era un tema amb molt poc suc i em va aconsellar de treballar sobre el tema de la màgia i la bruixeria, que podria ser més interessant pels seus lligams amb la medicina tradicional i amb molts altres temes més actuals. Va ser un bon consell. Però sobre el joc hi anava treballant a estones perdudes, fins que va arribar el moment de la jubilació, que és com estic jo ara, en que vaig disposar de tot el temps que volia. I ara estic treballant sobre una epopeia africana, ja fa un parell d'anys que hi treballo. Veus això d'aquí darrera: és una mena de "guitarra africana", una arpa-cítara, un instrument musical amb què s'acompanyen els trobadors de mvet. 


\section{perifèria}

Número 17, desembre 2012

www. periferia.name

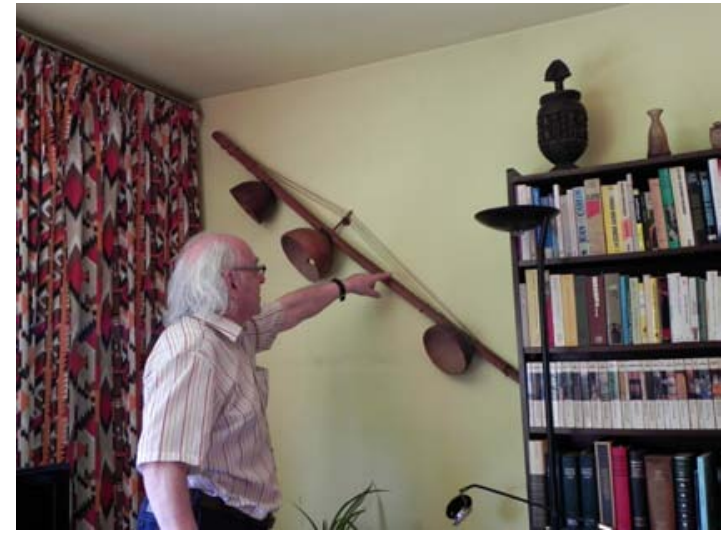

\section{P: Això ho va portar a un programa de TV3 ja fa molts anys.}

R: Sí. Això és una branca de palmera de ràfia i les cordes estan fetes d'escorça i han estat separades una a una. I n'hi ha una de recanvi i tot, que la podria canviar però no sé fer-ho. I això són carbasses i aquí hi han trossos de liana perquè no s'acabi de separar l'escorça de les cordes. I amb això van tocant els trobadors, que es poden passar una nit sencera cantant aquestes epopeies. Hi va haver un estudiant meu, en Pascal Boyer que ara ensenya als Estats Units, a qui vaig encoratjar per a que fes la seva tesi de doctorat sobre això i està publicada en francès. I a més a més a França hi ha una publicació molt ben feta als Classiques africains d'una epopeia d'aquestes amb el text fang. Jo conec l'ewondo però s'assembla al fang com el català al valencià. I ara estic fent un estudi sobre aquest relat èpic. És sobre dos pobles que lluiten entre si; els uns són mortals i els altres són immortals, diuen. Jo crec que això de la mortalitat i la immortalitat, sobretot la immortalitat, és un invent posterior, dels comentaristes d'aquest gènere de relat.

Ara, doncs, faig escrits sobre això i no sé què en sortirà. Aquesta epopeia és 


\section{perifèria}

Número 17, desembre 2012

www.periferia.name

una crítica contra el poder absolut, el poder colonial disfressat d'una altra manera. Però jo m'ho passo molt bé. Malgrat tot, tinc un problema de llengües també: no sé si fer-ho en català o en francès, perquè escric coses en català, altres en francès... En l'edició francesa hi ha el text en la llengua fang i la traducció francesa: són 1500 versos. Llavors he fet un resum en català de tota l'epopeia - que té setanta planes el resum!-, perquè si un dia publico els comentaris la gent sàpiga de què va l'epopeia... se n'enteri. Una cosa que us dic a vosaltres que sou joves és que us guardeu feina per quan estigueu jubilats, per estar ben ocupats!

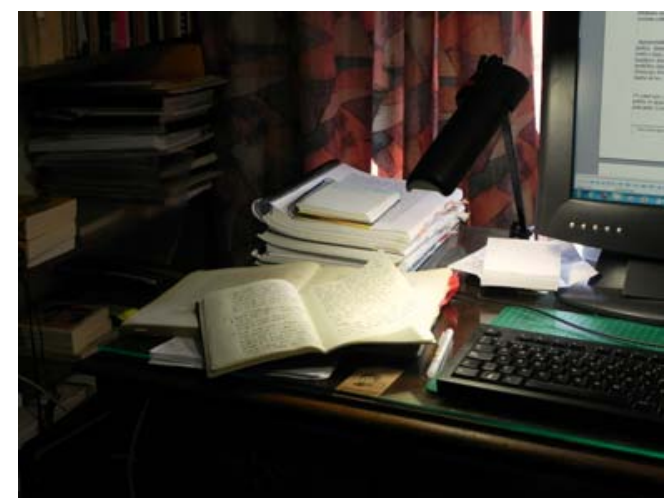

\section{P: A Sóc fill dels evuzok vostè escriu que l'antropologia és l'art de perdre el temps. Creu que això és possible de fer en l'antropologia d'avui en dia?}

R: No és possible en el sentit de les institucions que et donen els diners, perquè si tu demanes un ajut econòmic per anar a perdre el temps a l'Àfrica no te'ls donaran. Però tu inventa't el què sigui per obtenir l'ajut. Jo crec que sí que és possible. Encara que l'altre dia parlava amb aquest estudiant meu que venia d'Estats Units i que volia anar a fer treball de camp a l'Àfrica i em 


\section{perifèria}

Número 17, desembre 2012

www.periferia.name

deia que avui no és tant fàcil d'anar a un lloc i dir: sóc etnòleg. Primer no t'entenen i has de fer etnologia i és molt difícil. Jo vaig tenir unes condicions immillorables i certament que el vaig perdre el temps, però fent etnologia. Allò d'anar a prendre vi, d'anar a casa d'un a casa de l'altre, prendre notes a casa,... amb grans, joves i no tan joves..., fer veure que no estàs fent res, però ho estàs fent. Vas aprenent de mica en mica les maneres de dir i de fer de la gent... Jo podia fer-ho. Vivia en unes circumstàncies especials. Jo crec que fer etnografia és una manera de viure, d'estar amb la gent, i de no tenir presses. I a vegades ho penso i us ho dic i ho escric. Imagineu-vos la persona que demana una beca per anar a l'Àfrica a estudiar els rituals funeraris. I la Generalitat molt generosa li ofereix una beca de tres o quatre mesos; i llavors ell va allí i resulta que durant la seva estada no es mor ningú...! I ja estàs desitjant que es mori algú! Perquè dius: "Ara com ho justifico jo això, si no n'he vist cap de cerimònia?"

Els temps han canviat a l'Àfrica però potser no tant com ens volen fer creure a vegades. A l'Àfrica jo crec que hi ha molt camp pels antropòlegs. Pots anar allà a través d'una ONG i al mateix temps, anar fent antropologia. Ara, si a l'ONG saben que tu ets antropòleg, potser no t'agafaran. És vergonyós que hi hagi moltes ONG que es dediquin a la cosa sanitària, per exemple, sense saber-ne res de la medicina autòctona d'aquells països...! I van tant segurs de la seva pròpia medicina, que ignoren la que passa al costat, que és la medicina tradicional. La pel-lícula de La Dansa dels esperits està filmada fa dos o tres anys sobre la mateixa persona sobre la qual l'any 82 vaig escriure el llibre sobre la iniciació i la pràctica ritual-medecinal d'aquest medecinaire, Mba Owona. Jo els hi explicava als meus nanos quan eren petits les aparicions i els esperits. És clar que hi feia aparèixer 


\section{perifèria}

Número 17, desembre 2012

www.periferia.name

molts més esperits...! Quan vam anar allà al Camerun per acomiadar-me de la gent i els meus fills van venir amb mi, em deien: "Qui és I'Mba Owona?" Era com un personatge fantàstic per a ells. I el què va significar per a ells d'arribar a aquest poble i tocar-lo, veure que allò que els hi explicava el seu pare era veritat... I només va faltar que ell els va dir: "Veniu veniu!" i va portar una fotografia de quan eren petits. El que es veu a la pel·lícula es el que es fa ara.

Ara no sé com pot anar un antropòleg i instal·lar-se allà, però és qüestió de fer-ho, de saber-ho fer. Jo diria que el món rural existeix a l'Àfrica i a moltes bandes del món. Ara bé, l'important és el que diu Jeanne FavretSaada: l'important per a l'antropòleg és que la gent ha de donar-te un estatus. Tu estàs allà i, què ets? Un enviat del govern? La gent necessita saber qui ets i què hi fas allà. Jo ho tenia més fàcil quan era capellà; m'era més fàcil de fer d'antropòleg que després, perquè el meu estatus quedava clar per la gent. Però després hi havia anat amb estudiants i col-legues i ja no estava tant clar. Tu què fas? Antropologia.

$\mathrm{Hi}$ ha gent que també es pensa que nosaltres ens fem milionaris amb els llibres que publiquem. Per a la gent d'allí és un tresor un llibre. Per als universitaris africans potser no, ja sabran les dificultats que hi ha per publicar alguna cosa. Però per a la gent del camp un Ilibre és... Llavors passa una cosa que la dèiem l'altre dia amb aquest company antropòleg, el Michael Houseman, que és d'origen americà però que està a França i que havia estat estudiant meu. Ell va treballar sobre el tema del parentiu entre els evuzokk i una vegada van donar-li alguna referència els evuzok que era treta d'un llibre meu! També li havia passat quelcom semblant al meu amic i col·lega Olivier Herrensmidt que treballava a l'Índia i que em deia que 


\section{perifèria}

Número 17, desembre 2012

www.periferia.name

quan la gent anaven a fer un sacrifici li preguntaven a ell: "El nostre pare com t'ho deia a tu que s'havia de fer el sacrifici aquest?"

\section{P: Té algun consell per als futurs llicenciats en antropologia?}

R: Que continueu, que no us desanimeu, que val la pena. La meva experiència ha sigut tant positiva...! M'ho he passat tant bé que avui, un cop jubilat, encara continuo. Ara, si voleu sortir a l'Hola i guanyar molts diners... no us en feu. Hem tingut sort tots nosaltres de poder estar en algun estament de l'acadèmia, de la manera com sigui, amb totes les trifulgues i tot, i poder fer el que realment ens agradava fer...

Ara, arriba un moment en que no pots parlar-ne massa. Tu te'n vas a viure a un Iloc com Olot (que a mi m'agrada molt, és el país de la meva dona), però amb els veïns no en pots parlar de l'antropologia. A la Biblioteca un dia em vaig trobar el Sóc fill dels evuzok que es venia per un euro! M'ho va dir el Ricard Creus, que ha guanyat un Sant Jordi, perquè el seu llibre també hi era per un euro...! Són llibres que no treu ningú i es posen a la venda...!!! Li vaig escriure una carta a la bibliotecària, que la coneixia i li vaig dir: “Home, una mica de consideració pels de Can Fanga!". Que aquí a Olot ens diuen els de Can Fanga als de Barcelona que estem aquí. Clar no pots explicar-los què faig i a què em dedico. No els hi pots dir: "Em dedico a l'epopeia dels fang..." A la biblioteca d'Olot pots anar-hi per treure novel-les o llibres d'història encara, però d'antropologia no tenen res. Llavors tens que limitar-te molt. També és lògic i normal. Tu perquè has tingut l'amabilitat de fer venir els teus estudiants aquí ${ }^{7}$, però jo ja estic jubilat i a

\footnotetext{
${ }^{7}$ Es refereix a la professora Montserrat Clua, directora del projecte.
} 


\section{perifèria}

Número 17, desembre 2012

www.periferia.name

les universitat no hi vaig a fer res... Els estudis africans a Espanya en general estan molt Iluny del que haurien d'estar, però sembla que Àfrica no interessa gaire... Jo collaboro amb l'equip de CEIBA on una colla d'antropòlegs africanistes fan coses interessants amb la col·laboració del CSIC de Barcelona... A Tarragona vam intentar fer quelcom en el camp de l'ensenyament i de la recerca. Va tenir prou èxit i força alumnes... Però quan va ser l'hora d'iniciar programes de recerca no es va poder tirar endavant...

En fi, potser que ho deixem aquí...

Moltes gràcies pel seu temps i la seva hospitalitat! Ha estat un plaer.

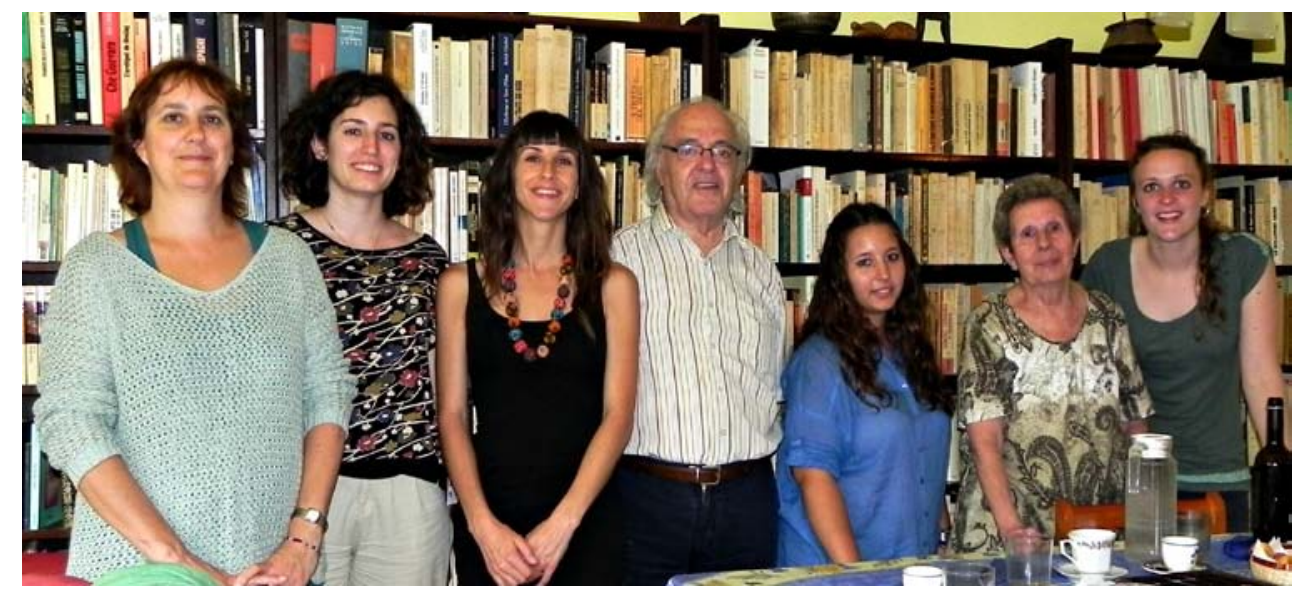

Fotografia de dreta a esquerra:

Eugènia Dallari, Neus Brussosa, Maria Nisa, Lluís Mallart, Marta Romogosa, Alèxia Rué i Montserrat Clua 